\section{UK ophthalmology electronic medical records, databases, big data, and Robert L Johnston!}

WM Amoaku
The value of audits and Big Data in ophthalmology continues to increase. Ophthalmic databases have been in use in different health systems for a while now. In the UK, electronic medical record (EMR) system or database had been used in selected hospitals for a long time. ${ }^{1}$ As with any new development, there are early, and late adopters, as well as the non-adopters. Several years ago, it was suggested in the Royal College of Ophthalmologists' Commissioning Guidelines for Contemporary Age-related Macular Degeneration (AMD) Services that 'data capture and management personnel were important for internal and external audits, as well as resource management'. Other recommendations on electronic records followed.

Not unexpectedly, commissioners have started asking 'why there is considerable variation in the number of anti-VEGF injections given in different Trusts or hospitals and why some centres do not seem to discharge patients from their Macular Clinics'. Some even wondered whether 'consensus had been developed about treatment regimen for neovascular AMD (nAMD) and other retinal conditions?' The intended question really, in my view, was 'why some clinicians/centres were over-treating compared to others?' My response, therefore, included the following: 'The significant variation in the number of injections is because more clinicians are undertreating rather than others over-treating. The other part of the problem is lack of capacity to see patients at the recommenced intervals. Definite consensus exists on re-treatment criteria. What may vary is clinician interpretation of the guidelines, and/or lack of capacity to see patients at the recommended time intervals with the seemingly resultant variation in practice.'

The solution to avoiding significant variation is clear cut (and different from what 'payers' may think): adequate capacity is required to allow optimal review and treatment, irrespective of whether the clinician adopts pro re nata (prn) or 'Treat and Extend' (T\&E) regimen, especially for nAMD. The T\&E regimen requires that the appointment system is more robust, and that there may be as many as $7-8$ treatments in year 1 (1 more than with prn regimen average) for patients with nAMD. However, the T\&E may assure better outcomes.

It is gratifying to note that UK data collection has stretched well beyond nAMD management, irrespective of what particular EMR system or database is used.

Talks $e t a l, 2$ in their paper on the 'Appropriateness of quality standards in AMD', report on aspects of clinical management in nAMD based on large audit data from the UK. The paper reports that significant variation was found amongst 16 nAMD treatment sites that provided the same therapeutic regime with aflibercept in nAMD. Previous reports on intercentre variation on the use of ranibizumab for the same indication have been published.

Similarly, these audits have confirmed that the visual acuity (VA) at treatment commencement significantly influenced outcomes, although all patients (and VAs) benefited from treatment for nAMD. ${ }^{3}$ These reports confirmed what was known anecdotally, that there were differences in treatment numbers, patient retention rates and discharge policies at the different sites. Although these may represent differences in the quality of care of patients, they could also reflect differences in population characteristics as well as difficulties in recording standardized comparable VA measures, or differences in clinical approach, such as being more or less
Academic Ophthalmology, Division of Clinical Neurosciences, 'B' Floor, EENT Centre, Queen's Medical Centre, University of Nottingham, Nottingham, UK

\section{Correspondence:}

WM Amoaku, Academic Ophthalmology, Division of Clinical Neurosciences, B Floor, EENT Centre, Queen's Medical Centre, University of Nottingham, Nottingham, UK Tel: +44 (0)11595 15151; Fax: +44 (0)1159627765. E-mail:wma@nottingham. ac.uk 
willing to start patients on therapy and continuing patient follow up with lower VA levels. For fairer comparisons between sites it is, therefore, recommended that both VA measures and process measures, such as injection numbers, retention rates and discharge policies are used. Such comparisons are easier with the adoption of EMR.

The late Robert L Johnston, Consultant Ophthalmologist in Gloucester and Cheltenham NHS Trust, who was dedicated to the delivery of excellent ophthalmic care, made significant contributions to EMR systems, real life data, big data and multicentre audits in the UK. His clinical and academic work, particularly following the electronic datasets developed and generated by Medisoft, have been ground-breaking. With the help of the EMR, he was one of a few selected clinicians who had the early realisation that there were capacity issues with retinal services, and championed alternative working practices in his Retina Service. His tireless efforts set the stage for the UK to lead the world in big data approaches to ophthalmology. This cultural shift in the way the eye care team document eye health, treatments and outcomes has led to better care for many thousands of patients with blinding conditions. Publications of very high clinical relevance continue to stream out from the UK following Rob's huge influence. He has contributed significantly to the UK National Ophthalmology Database projects (of the RCOphth) as shown by the number of publications of very high clinical relevance that resulted and continue to stream out from the UK following Rob's huge influence. These include at least 22 publications to date (including the paper by Talks et $a l^{2}$ ) in Eye, and others in other highly regarded peer reviewed journals. His the 'Do Once and Share' project for diabetic retinopathy, which first reported in 2006 was incorporated into our routine electronic clinic records, so that we now have world-leading UK outcomes data. ${ }^{4}$ The data on hospital occurrence of dry AMD also collected through the Medisoft EMR should be published soon.

Rob was always incisive, but easy to work with, and always accommodating of others' positions, as well as being very generous. The week before his demise, he was even apologising to a colleague for his inability to meet up as arranged because he was poorly! This is well summarised by a quote from another colleague (Clare Bailey) who surmised that 'Rob's love of his work was evident in everything that he did. What I found particularly inspirational was his continuing enormous levels of contribution and commitment, despite his deteriorating health last summer. He was contributing to papers, attending meetings and selflessly offering his wise advice, right until the end.'

Although the Retinal fraternity claim him as one of their own, his contributions go well beyond, across all ophthalmology into cataracts, uveitis, and glaucoma, as well as non-medical ophthalmology, and primary care. He has left a lasting legacy, through transformation of the way we work as ophthalmologists (especially), allied eye care staff, and eye care administrators/managers in the UK that will be remembered for a long time!

We need to remember, however, that with any innovation (including dynamite for the construction industry), there are uses that the innovation was not intended for: good and bad. We have to remain vigilant, and endeavour to avoid the bad usage of EMR including attempts to adopt it as a policing tool!

\section{Conflict of interest}

WMA is a consultant for Alimera, Allergan Inc., Bayer, Novartis, Pfizer, Roche, Santen, and Thrombogenics, and has undertaken research sponsored by Allergan,

Novartis, and Pfizer. He has received speaker fees and travel grants from Allergan, Bausch and Lomb, Bayer, Novartis and Pfizer.

\section{References}

1 Johnston RL, Sparrow JM, Canning C, Tole D, Price NC. UK Cataract EPR Users Group. Pilot National Electronic Cataract Surgery Survey: I. Method, descriptive, and process features. Eye 2005; 19: 788-794.

2 Talks JS, James P, Sivaprasad S, Johnston RL, McKibbin M for the UK aflibercept users group. Appropriateness of quality standards for meaningful intercentre comparisons of aflibercept service provision for neovascular age-related macular degeneration. Eye (Lond) 2017; 31: 1613-1620.

3 Lee AY, Lee CS, Butt T, Xing W, Johnston RL, Chakravarthy U et al. UK AMD EMR USERS GROUP REPORT V: benefits of initiating ranibizumab therapy for neovascular AMD in eyes with vision better than 6/12. Br J Ophthalmol 2015; 99: 1045-1050.

4 The Do Once and Share Connecting for Health Initiative. Available at: https://www.rcophth.ac.uk/wp-content/ uploads/2015/09/Diabetic-Eye-Disease-Action-Team-FinalReport-Version-1-0.pdf and http://webarchive. nationalarchives.gov.uk/20130502102046/http:/ / www. connectingforhealth.nhs.uk/resources/systserv/ do-once-and. 